\title{
O Que É Ensino Colaborativo? ${ }^{1}$ What Is Colaborative TeACHING?
}

\author{
Camila Elidia Messias dos SANTOS ${ }^{2}$ \\ Lorinisa Knaak da COSTA ${ }^{3}$
}

\begin{abstract}
RESUMO: A obra O que é Ensino Colaborativo? propõe divulgar os conhecimentos científicos em uma linguagem mais acessível para os professores, permitindo que revejam suas práticas pedagógicas, com o objetivo de torná-las mais inclusivas. De modo dinâmico e ilustrativo, o estudo foi organizado em cinco capítulos. No primeiro, as autoras discorrem sobre as fundamentaçóes introdutórias referentes à Educação Especial na perspectiva da Educação Inclusiva. Nos capítulos subsequentes, o Ensino Colaborativo é apresentado de forma esclarecedora, aludindo ao seu conceito, suas características e como ele pode ser implementado. O quarto capítulo trata das reflexóes sobre a escola inclusiva, os papéis e as responsabilidades de cada profissional para o desenvolvimento do currículo escolar. A obra é complementada com experiências de pesquisas sobre o Ensino Colaborativo realizadas no Brasil. Nas considerações finais, são destacados alguns questionamentos e reflexões acerca da adoção do Ensino Colaborativo. Por último, é apresentada uma seção com dúvidas frequentes expressas por professores e equipe escolar, quando a escola opta pelo trabalho em colaboração e inicia sua implementação.
\end{abstract}

PALAVRAS-CHAVE: Educação Especial. Educação Inclusiva. Prática pedagógica.

\begin{abstract}
The work What is Collaborative Teaching? intends to disseminate scientific knowledge in a more accessible language for teachers, allowing them to review their pedagogical practices, with the aim of making them more inclusive. In a dynamic and illustrative way, the study was organized into five chapters. In the first, the authors discuss the introductory foundations referring to Special Education from the perspective of Inclusive Education. In the subsequent chapters, Collaborative Teaching is presented in an illuminating way, alluding to its concept, its characteristics and how it can be implemented. The fourth chapter deals with reflections on the inclusive school, the roles and responsibilities of each professional for the development of the school curriculum. The work is complemented with research experiences on Collaborative Teaching carried out in Brazil. In the final considerations, some questions and reflections about the adoption of Collaborative Teaching are highlighted. Finally, a section with frequent doubts expressed by teachers and school staff is presented, when the school chooses to work in collaboration and starts its implementation.
\end{abstract}

KEYWORDS: Special Education. Inclusive Education. Pedagogical practice.

\section{O Que É Ensino Colaborativo?}

A ampliação do acesso dos estudantes da Educação Especial às escolas de ensino comum possibilitou uma mudança de foco, dando origem ao movimento de inclusáo escolar. $\mathrm{Na}$ perspectiva da Educação Inclusiva, todos os estudantes, com ou sem deficiência, passaram a ser ensinados na mesma sala. Assim, as escolas vivem um constante desafio de reorganizarem-se, para atender aos estudantes e não o contrário. O Ensino Colaborativo surge como um trabalho de parceria entre o professor de ensino comum e o professor de Educaçáo Especial, dividindo a responsabilidade do ensino, considerando as especificidades, os ritmos e os estilos de aprendizado, para favorecer o acesso e a aprendizagem de todos, inclusive dos alunos Público-Alvo da Educação Especial (PAEE).

\footnotetext{
${ }^{1}$ https://doi.org/10.1590/1980-54702020v26e0129

2 Doutoranda em Psicologia do Desenvolvimento e Aprendizagem. Universidade Estadual Paulista "Júlio de Mesquita Filho" (UNESP/Bauru). Bauru/São Paulo/Brasil. E-mail: kmila_messias@hotmail.com. ORCID: https://orcid.org/0000-0003-14289899

${ }^{3}$ Mestranda em Docência para a Educação Básica. Universidade Estadual Paulista “Júlio de Mesquita Filho" (UNESP/Bauru). Bauru/São Paulo/Brasil. E-mail: lorinisaknaakdacosta@gmail.br. ORCID: https://orcid.org/0000-0002-9676-7323
} 
Nos últimos anos, a colaboração entre profissionais tem se tornado essencial para o alcance das metas da Educação Inclusiva. Desse modo, a obra $O$ que é Ensino Colaborativo?, elaborada a partir das pesquisas de Mestrado de Ana Paula Zerbato e de Doutorado de Vera Lucia Messias Fialho Capellini, produzidas no âmbito do Grupo de Pesquisa Formação de Recursos Humanos em Educação Especial (GP - FOREESP), sob a orientação da Prof. ${ }^{a}$ Dr. ${ }^{a}$ Enicéia Gonçalves Mendes, propóe divulgar os conhecimentos científicos em uma linguagem mais acessível para os professores, permitindo que revejam suas práticas pedagógicas, com o objetivo de torná-las mais inclusivas (Capellini \& Zerbato, 2019).

De modo dinâmico e ilustrado, o estudo foi organizado em cinco capítulos. No primeiro, as autoras discorrem sobre as fundamentações teóricas e introdutórias referentes à Educação Especial na perspectiva da Educação Inclusiva e ao seu público, de acordo com as políticas brasileiras vigentes. Nos capítulos subsequentes, o Ensino Colaborativo é apresentado de forma esclarecedora. Que tal aprender agora o que é um Ensino Colaborativo? alude ao conceito de Ensino Colaborativo, suas características e como ele pode ser implementado. Modelos de implementação do Ensino Colaborativo aborda os diferentes modelos do Ensino Colaborativo que podem ser realizados em sala de aula, além das principais dimensóes necessárias para a sua aplicação na escola comum.

Ensino colaborativo e inclusão escolar: e agora, a responsabilidade é de quem? trata das reflexóes sobre a escola inclusiva, os papéis e as responsabilidades do professor do Ensino Comum, da Educação Especial e de ambos, para o desenvolvimento do currículo escolar e a concretização do Ensino Colaborativo. O papel da gestão escolar é destacado como imprescindível para a sua efetivação. No quinto capítulo, a obra é complementada com experiências de pesquisas sobre o Ensino Colaborativo realizadas no Brasil. Nas consideraçóes finais, são destacados alguns questionamentos e reflexóes acerca da adoção do Ensino Colaborativo. Apesar de sua implementação depender de investimentos em recursos que deem suporte ao professor de Educação Especial, a fim de atuar em conjunto com o professor da classe comum, a escola que deseja se tornar inclusiva deve lançar meios de oferta de formação inicial e continuada e a garantia da execução de um trabalho colaborativo.

Por último, é apresentada uma seção com dúvidas frequentes expressas por professores e equipe escolar, quando a escola opta pelo trabalho em colaboração e inicia sua implementação. Essa seção reforça a proposta do livro, uma vez que visa a minimizar as principais dificuldades que possam ser encontradas na prática, tornando-se, assim, um excelente guia para a atuação dos professores.

\section{REFERÊNCIA}

Capellini, V. L. M. F., \& Zerbato, A. P. (2019). O que é Ensino Colaborativo?. São Paulo: Edicon.

Recebido em: 18/05/2020

Reformulado em: 03/07/2020

Aprovado em: 06/07/2020 